Transparent Conductive Tantalum Doped Tin Oxide as Selectively SolarTransmitting Coating for High Temperature Solar Thermal Applications

Lungwitz, F.; Escobar-Galindo, R.; Janke, D.; Schumann, E.; Wenisch, R.; Gemming, S.; Krause, M.;

Publiziert:

März 2019

Solar Energy Materials and Solar Cells 196(2019), 84-93

DOI: https://doi.org/10.1016/j.solmat.2019.03.012

Perma-Link zur HZDR-Publikationsdatenbank

https://www.hzdr.de/publications/Publ-28957

CC-BY-NC-ND 4.0

Internet-Freigabe ausstehend 


\title{
Transparent Conductive Tantalum Doped Tin Oxide as Selectively Solar- Transmitting Coating for High Temperature Solar Thermal Applications
}

\author{
Frank Lungwitz ${ }^{\mathrm{a}}$, Ramon Escobar-Galindo ${ }^{\mathrm{b}}$, Daniel Janke ${ }^{\mathrm{a}}$, Erik Schumann ${ }^{\mathrm{a}}$, Robert Wenisch ${ }^{\mathrm{a}, 1}$, Sibylle \\ Gemming $^{\mathrm{a}, \mathrm{c}}$, Matthias Krause ${ }^{\mathrm{a}, *}$ \\ ${ }^{a}$ Helmholtz-Zentrum Dresden-Rossendorf, Institut für Ionenstrahlphysik und Materialforschung, Bautzner Landstraße \\ 400, 01328 Dresden, Germany \\ ${ }^{b}$ Departamento de Ciencia de los Materiales e Ingeniería Metalúrgica y Química Inorgánica - IMEYMAT, Universidad de \\ Cádiz, 11510 Puerto Real, Spain \\ ${ }^{c}$ Technische Universität Chemnitz, Institut für Physik, Reichenhainer Str. 70, 09126 Chemnitz, Germany \\ *matthias.krause@hzdr.de
}

\begin{abstract}
The transparent conductive oxide (TCO) $\mathrm{SnO}_{2}: \mathrm{Ta}$ is developed as a selectively solar-transmitting coating for concentrated solar power (CSP) absorbers. Upon covering with an antireflective layer, a calculated absorptivity of $95 \%$ and an emissivity of $30 \%$ are achieved for the model configuration of $\mathrm{SnO}_{2}: \mathrm{Ta}$ on top of a perfect black body (BB). High-temperature stability of the developed TCO up to $1073 \mathrm{~K}$ is shown in situ by spectroscopic ellipsometry and Rutherford backscattering spectrometry. The universality of the concept is demonstrated by transforming silicon and glassy carbon from non-selective into solar-selective absorbers by depositing the TCO on top of them. Finally, the energy conversion efficiencies of $\mathrm{SnO}_{2}: \mathrm{Ta}$ on top of a $\mathrm{BB}$ and an ideal non-selective BB absorber are extensively compared as a function of solar concentration factor $C$ and absorber temperature $T_{\mathrm{H}}$. Equal CSP efficiencies can be achieved by the TCO on BB configuration with approximately $50 \%$ lower solar concentration. This improvement could be used to reduce the number of mirrors in a solar plant, and thus, the levelized costs of electricity for CSP technology.

Keywords: concentrated solar power, solar thermal electricity, solar-selective transmitter, transparent conductive oxide, high-temperature in situ characterization
\end{abstract}

\footnotetext{
${ }^{1}$ Current address: Helmholtz-Zentrum Berlin für Materialien und Energie GmbH, Hahn-Meitner-Platz 1, D-14109 Berlin
} 


\section{Introduction}

Concentrating solar power (CSP) or solar thermal electricity (STE) is a commercially available technology in the emerging field of renewable energies. It is based on the concentration of sunlight onto an absorbing receiver, the transfer of the generated heat to a fluid and the subsequent conversion of thermal energy into electrical energy via a heat exchanger, steam turbine and electrical power generator. Currently, the most important CSP plant systems are parabolic trough collectors and central receiver towers, operated at up to $673 \mathrm{~K}$ and $873 \mathrm{~K}$ respectively [1]. In order to enhance their energy conversion efficiency, higher operation temperatures are required. Additionally, based on physical limits outlined later on, solar selectivity is indispensable to enhance the performance of solar thermal power plants, as emphasized in the reviews of Kennedy [2], Granqvist [3,4] and Weinstein [5].

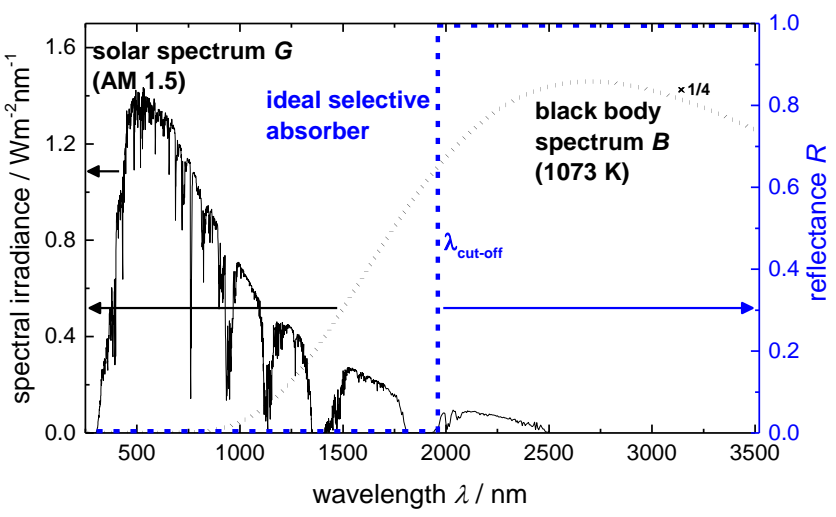

Fig. 1. Solar spectrum AM 1.5 and black body spectrum (divided by 4 for better visibility) at 1073 K calculated by Planck's law. The blue dashed line shows reflectance $R$ of an ideal selective absorber. The wavelength at which the ideal selective absorber switches from non-reflective to reflective is called cut-off wavelength $\lambda_{\text {cut-off. }}$

The concept of solar selectivity utilizes the different characteristic wavelength ranges of solar spectrum and thermal radiation. Translated into the terminology of CSP, the absorption of solar light occurs at much shorter wavelengths than the radiative emission of a black body $B(\lambda)$ which it heats (Fig. 1). The solar spectrum $G(\lambda)$ with the air mass coefficient (AM) 1.5 represents the yearly average of solar irradiance at mid-latitudes on the surface of the earth [6]. It can be approximated by the emissivity of a black body (BB) at $T=5777 \mathrm{~K}$ calculated by Planck's law, taking into account the intensity reduction due to the small solid angle and atmospheric absorption losses [7, 8]. Its intensity maximum at $515 \mathrm{~nm}$ occurs at a much shorter wavelength than that of a $\mathrm{BB}$ at $T=1073 \mathrm{~K}\left(\lambda_{\max } \approx\right.$ $2700 \mathrm{~nm}$ ), the target temperature of current research and development for CSP tower plants (Fig. 1) [9, 10]. The energetic separation of the peak intensities can be used to design solar-selective coatings (SSCs) resembling the ideal characteristics, i.e., very low reflectance $R$ in the range of the solar spectrum and high reflectance in the range of the BB radiation (blue dashed line in Fig. 1). The wavelength at which the coating switches from non-reflective to reflective is called cut-off wavelength, $\lambda_{\text {cut-off. }}$ Equation 1a and 1b show the standard definitions of the two crucial material parameters of CSP, absorptivity $\alpha$ and emissivity $\varepsilon[9,10]$.

$$
\alpha=\frac{\int_{300 \mathrm{~nm}}^{2500 \mathrm{~nm}}[1-R(\lambda)] G(\lambda) d \lambda}{\int_{300 \mathrm{~nm}}^{2500 \mathrm{~nm}} G(\lambda) d \lambda}
$$




$$
\varepsilon=\frac{\int_{1000 \mathrm{~nm}}^{2500 \mathrm{~nm}}[1-R(\lambda, T)] B(\lambda, T) d \lambda}{\int_{1000 \mathrm{~nm}}^{2500 \mathrm{~nm}} B(\lambda, T) d \lambda}
$$

Using $\alpha$ and $\varepsilon$, the efficiency $\eta$ for the conversion of solar energy into mechanical energy can be calculated by

\section{Equation 2:}

$$
\eta=\eta_{\text {opt }} \cdot \eta_{\text {Carnot }}=\left(\alpha-\frac{\varepsilon \sigma\left(T_{H}^{4}-T_{a m b}^{4}\right)}{I C}\right)\left(1-\frac{T_{a m b}}{T_{H}}\right)
$$

where $\sigma$ is the Stefan-Boltzmann constant, $T_{\mathrm{H}}$ the absorber temperature, $T_{\text {amb }}$ the ambient temperature, $I$ the integrated solar irradiance and $C$ the sun concentration factor, given by the ratio of collecting and absorbing area in a solar plant. The first term of Equation 2 is called optical efficiency; the second term represents the Carnot cycle efficiency. Clearly, a CSP absorber coating should have a high absorptivity and low emissivity at a given temperature. Nevertheless, it has to be noted that the absorptivity has a much larger influence on the efficiency compared to the emissivity. Inserting the values for $\sigma$ and $I=892 \mathrm{~W} / \mathrm{m}^{2}$, which corresponds to AM 1.5 , and assuming $T_{\mathrm{H}}=1073 \mathrm{~K}, T_{\mathrm{amb}}=303 \mathrm{~K}$ and $C=1000$, the ratio of emissivity and absorptivity in Equation 2 is only 0.08 . This means, a solar-selective transmitter under these conditions can only be useful if it decreases the bare BB emissivity by at least 13 times the TCO-induced absorptivity loss.

Selectivity can be achieved by different designs of the absorber coating. The most intensively studied solar selective materials for temperatures up to $673 \mathrm{~K}-773 \mathrm{~K}$ are metal-dielectric multilayers [13-15], ceramic-metal composites (cermets) $[16,17]$ and semiconductor-metal tandems [18]. Some of these are already commercialized [19]. Very recent research on multilayer [7,20] or composite SSCs [21] addressed even temperatures in the range up to $1000 \mathrm{~K}$. Textured surfaces [22] and selective transmitters [23] can also provide solar selectivity. The application of transparent conductive oxides (TCOs) for low emissivity glasses was studied intensively as shown in the work of Granqvist [4], but only a few studies using TCOs on an absorbing substrate were published. Fan and Bachner reported on $\operatorname{In}_{2} \mathrm{O}_{3}$ :Sn thin films with $\alpha=0.90$ and $\varepsilon=0.081$ (at $394 \mathrm{~K}$ ) as well as on $\operatorname{In}_{2} \mathrm{O}_{3}: \mathrm{Sn}$ coated with a $100 \mathrm{~nm} \mathrm{MgF}_{2}$ anti-reflection layer with $\alpha=0.85$ and $\varepsilon=0.081$ (at $394 \mathrm{~K}$ ), assuming a perfect BB substrate [24]. $\mathrm{SnO}_{2}: \mathrm{F}$ prepared by spray pyrolysis at $1113 \mathrm{~K}$ on black enameled steel was investigated in the work of Haitjema et al. [25]. It exhibited $\alpha=0.91$ and $\varepsilon=0.15$, and was thermally stable up to $523 \mathrm{~K}$ for 6 weeks and up to $673 \mathrm{~K}$ for 8 days in air, respectively. Shimidzu et al. deposited $\mathrm{In}_{2} \mathrm{O}_{3}: \mathrm{Sn}$ on a tungsten substrate and reported $\alpha$ $=0.71$ as well as emissivities of $\varepsilon=0.08$ at $353 \mathrm{~K}$ and $\varepsilon=0.13$ at $973 \mathrm{~K}$. The stack was thermally stable at $973 \mathrm{~K}$ in vacuum for up to 10 hours when prepared with a $\mathrm{SiO}_{2}$ interlayer between metal substrate and TCO [26]. Taylor et al. studied a wide range of TCOs including F-, Sb- and Cd-doped $\mathrm{SnO}_{2}$ (FTO, ATO, CTO), Sn doped $\mathrm{In}_{2} \mathrm{O}_{3}$ (ITO) and B-, Al-, Ga- and F-doped ZnO (BZO, AZO, GZO, FZO) [23]. In that theoretical study, ITO and FTO showed the best solar selectivity in the temperature range up to $873 \mathrm{~K}$.

However, none of the previous studies reported on any coating with very low reflectance in the solar spectral range and, consequently, $\alpha \geq 0.95$ on a BB substrate in combination with thermal stability up to at least $1073 \mathrm{~K}$. Moreover, the parameter space of $T_{\mathrm{H}}$ and $C$, where TCOs are beneficial for CSP, has not been explored yet. Hence, an investigation of the TCO on BB configuration as alternative concept for CSP plants of the next generation is lacking so far. 
In this work, a Ta-doped $\mathrm{SnO}_{2} \mathrm{TCO}$ on top of a $\mathrm{BB}$ is developed as selectively solar-transmitting coating for high temperature CSP technology. In addition to its excellent TCO properties, the material selection is based on the demand for thermal, chemical, mechanical and environmental/chemical stability (such as oxidation stability and resistance to moisture), as well as for cost-effectiveness [27]. The results of ex situ optical, electrical and structural characterization by spectroscopic photometry, spectroscopic ellipsometry (SE), Hall-effect measurements and Rutherford backscattering spectrometry (RBS) were used to optimize the deposition temperature and dopant concentration. In situ $\mathrm{SE}$ and RBS were applied to prove thermal stability of $\mathrm{SnO}_{2}: \mathrm{Ta}$ at temperatures up to $1073 \mathrm{~K}$. An anti-reflective (AR) $\mathrm{SiO}_{2}$ top layer with appropriate thickness allows to achieve an absorptivity of $96 \%$ for the TCO on top of a BB configuration. As proof of concept, silicon and glassy carbon were transformed into solar-selective materials by covering them with the TCO. Finally, the advantages and limitations of the TCO on $\mathrm{BB}$ concept for high temperature CSP technology are discussed for a $\left(T_{\mathrm{H}}, C\right)$ parameter range that comprises the current and projected future solar plant operation conditions by comparing its efficiency with that of a non-selective BB absorber.

\section{Materials and methods}

$\mathrm{SnO}_{2}$ :Ta thin film samples were deposited by direct current reactive magnetron sputtering from two metallic 2" targets ( $\mathrm{Sn}$ (99.99 at.\%) and Sn:Ta (6.7 at.\% Ta)). Argon was used as sputter gas. The working pressure was varied between $0.9 \mathrm{~Pa}$ and $1.0 \mathrm{~Pa}$, and the oxygen partial pressure was fixed at $0.11 \mathrm{~Pa}$. Fused quartz was used as substrate for coating development in order to be able to perform optical measurements in reflection and transmission mode. The Ta concentration was varied from 0 to 1.8 at.\% by changing the sputtering powers. In a second sample series, the deposition temperature was varied from $710 \mathrm{~K}$ to $907 \mathrm{~K}$. Having optimized the TCO, silicon and glassy carbon substrates were coated for two reasons: i) to investigate the TCO properties on absorbing surfaces and ii) to study to which extend absorbers can be made solar-selective.

For optical characterization, specular reflectance at $5^{\circ}$ incidence angle and normal angle transmission were measured in the spectral range from $300 \mathrm{~nm}$ to $3000 \mathrm{~nm}$ using a SolidSpec 3700DUV spectrometer (Shimadzu). An M-2000 ellipsometer (Woollam) was used for SE measurements in the range from $211 \mathrm{~nm}$ to $1688 \mathrm{~nm}$. The WVASE32 software (Woollam) was applied for optical modelling of the measured data to obtain the optical constants, thickness and roughness of the studied coating materials, and moreover, for all the optical simulations in this work [28].

The thermal stability of the optimized $\mathrm{SnO}_{2}$ :Ta thin films was investigated under high vacuum conditions in a cluster tool $[29,30]$ installed at the 6 MV ion beamline of the Ion Beam Center of the HZDR [31]. Temperaturedependent in situ $\mathrm{SE}$ of $\mathrm{SnO}_{2}$ :Ta on fused quartz was recorded in the spectral range from $371 \mathrm{~nm}-1000 \mathrm{~nm}$ during a heating ramp of $15 \mathrm{~K} / \mathrm{min}$ from room temperature (RT) to $1073 \mathrm{~K}$. Temperature-dependent in situ RBS was performed using $2 \mathrm{MeV} \mathrm{He}$ ions with a beam current of $\sim 20 \mathrm{nA}$. The heating procedure consisted of three cycles, including heating the sample with $20 \mathrm{~K} / \mathrm{min}$ from RT to $1073 \mathrm{~K}$, keeping it at this temperature for $30 \mathrm{~min}\left(1^{\text {st }}\right.$ and $2^{\text {nd }}$ cycle) and $180 \mathrm{~min}$ ( $3^{\text {rd }}$ cycle) and then cooling it back to RT. In total, the sample was exposed to $1073 \mathrm{~K}$ ( 800 ${ }^{\circ} \mathrm{C}$ ) for four hours. The beam spot diameter on the sample was $<1 \mathrm{~mm}$. The backscattered ions were detected by a silicon surface barrier detector under an angle of $155^{\circ}$. 
The charge carrier density $N_{e}$ and the electrical charge carrier mobility $\mu_{\mathrm{el}}$ were determined by Hall-effect measurements using the van der Pauw method [32]. Every sample was measured five times to estimate a realistic error for those values.

\section{Results and discussion}

\subsection{Design and optimization of $\mathrm{SnO}_{2}:$ Ta as solar-selective transmitter}

As introduced in section $1, \lambda_{\text {cut-off }}$ is a crucial parameter for the design of solar-selective coatings. Because the solar spectrum and the high-temperature BB spectrum overlap, $\lambda_{\text {cut-off }}$ separates the spectral ranges of absorption and thermal emission of a selective absorber and thus, it determines the numerical values for $\alpha$ and $\varepsilon$ obtained by Equation 1a and $1 \mathrm{~b}$ (Fig. 2a). Assuming $\lambda_{\text {cut-off }}=2500 \mathrm{~nm}$, the sunlight is completely absorbed $(\alpha=1)$, but at the cost of losing $20 \%$ of the BB radiation due to thermal emission $(\varepsilon=0.2)$. For $\lambda_{\text {cut-off }}=1000 \mathrm{~nm}$, the thermal emission is completely suppressed $(\varepsilon=0)$, but only $73 \%$ of the sunlight is absorbed $(\alpha=0.73)$.
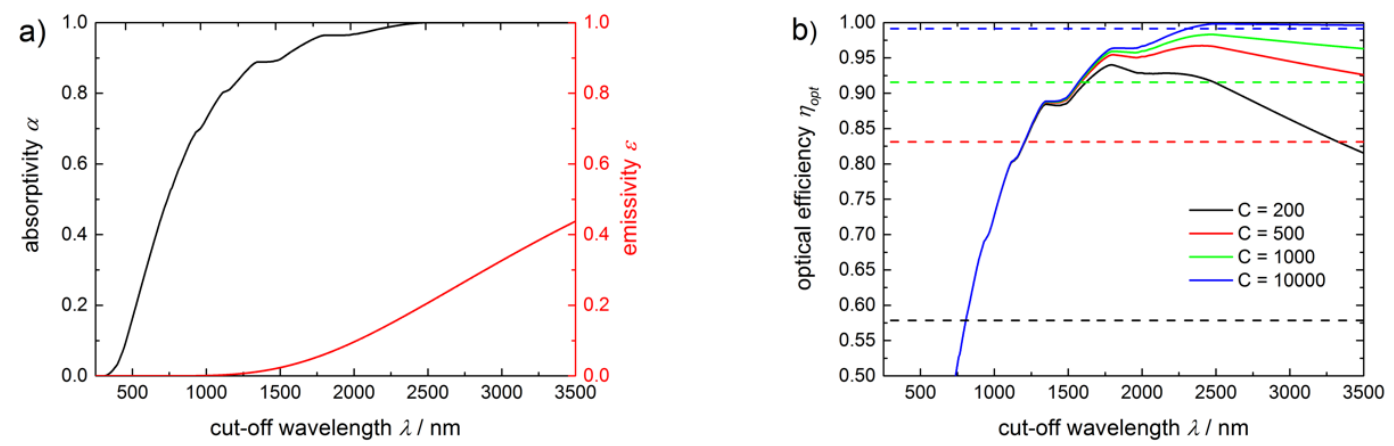

Fig. 2. a) Absorptivity $\alpha$ and emissivity $\varepsilon$ of an ideal selective absorber $\left(T_{H}=1073 \mathrm{~K}\right)$ in dependence of the cut-off wavelength $\lambda_{\text {cut-off }}$ and b) optical efficiency for four different concentration factors in dependence of $\lambda_{\text {cut-off }}$ calculated with $T_{H}=1073 \mathrm{~K}$, $T_{\mathrm{amb}}=303 \mathrm{~K}, I=892 \mathrm{~W} / \mathrm{m}^{2}$. The dashed lines represent the efficiency of a non-selective, perfect BB absorber $(\alpha=1, \varepsilon=1)$.

The effect of solar selectivity on the optical efficiency of solar absorbers is estimated according to Equation 2 for an absorber temperature of $1073 \mathrm{~K}$ and four different concentration factors, which are relevant for CSP plants

(Fig. 2b). The shape of the obtained functions is determined by i) the increase of $\alpha$ until the integration includes the complete solar spectrum up to $2500 \mathrm{~nm}$, ii) the efficiency-enhancing effect of an increasing concentration factor $\mathrm{C}$ and iii) the efficiency-reducing effect of the emissivity $\varepsilon$ in the infrared range. The dashed lines represent the efficiencies of a non-selective, perfect BB absorber $(\alpha=1, \varepsilon=1)$ for the different $C$ values. The intersection between the dashed and the solid line of each color represents the $\lambda_{\text {cut-off }}$ from which an ideal selective absorber is more efficient than the BB absorber alone. In general, solar selectivity improves the optical efficiency of a solar absorber, and hence, the total efficiency of CSP plant systems for a wide range of cut-off wavelengths and concentration factors by a substantial amount (Fig. 2b). An optimal optical efficiency of $\geq 90 \%$ is achieved when $\lambda_{\text {cut-off }}$ is between $1500 \mathrm{~nm}$ and $2500 \mathrm{~nm}$. The possibility of tuning the cut-off wavelength in order to match the optimized value for a given combination of absorber temperature and concentration factor would therefore be a significant progress for design and development of SSC's for CSP. 
It is a well-known fact from semiconductor physics that charge carrier density and mobility are responsible for the wavelength and slope of the reflectance edge in the absorption spectra [33,34]. Fig. 3a and 3b show simulated reflectance spectra of a doped $\mathrm{SnO}_{2}$ coating (thickness $500 \mathrm{~nm}$ ) on top of a transparent fused quartz substrate as a function of charge carrier concentration and mobility. The optical constants of the substrate have been determined by SE measurements and modelling. They correspond exactly to the $\mathrm{SiO}_{2}$ model [35] provided by the database of the WVASE32 optical modelling software [28]. The basic dielectric function of $\mathrm{SnO}_{2}$, described by a single Lorentz oscillator for the interband absorption, which was used for the simulation, is also obtained from the same database. It was extended by a Drude oscillator to account for the contribution of the dopant charge carriers to the conductivity. The two crucial material parameters, charge carrier density $N_{e}$ and optical charge carrier mobility $\mu_{\text {opt }}$, were varied in meaningful intervals in accordance to the values given in the work of Sago et al. [36] in order to show their influence on the reflectance. For better comparability, the effective electron mass was fixed at $m^{*}=$ $0.275 m_{0}$, although Sago et al. states a slight dependency of $m^{*}$ on $N_{e}\left(m^{*}=m_{0}\left(0.275+0.01 \times 10^{-20} \times N_{e}\right)\right)$, where $m_{0}$ is the free electron mass [36].
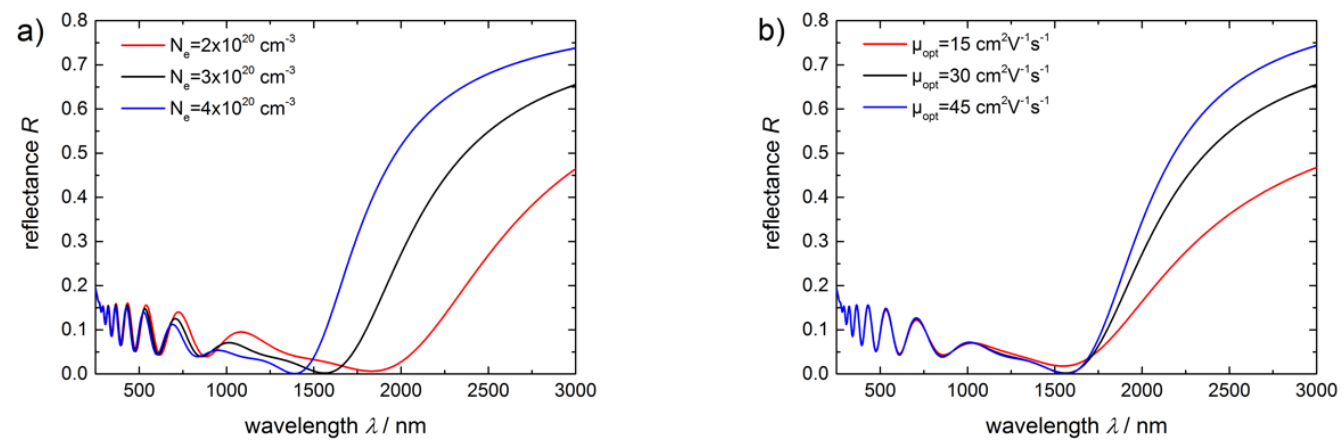

Fig. 3. Calculated reflectance $R$ of doped $\mathrm{SnO}_{2}(500 \mathrm{~nm})$ on fused quartz as a function of a) charge carrier density $N_{\mathrm{e}}$ at fixed optical charge carrier mobility $\mu_{\text {opt }}=30 \mathrm{~cm}^{2} \mathrm{~V}^{-1} \mathrm{~s}^{-1}$ and b) $\mu_{\text {opt }}$ at fixed $N_{e}=3 \times 10^{20} \mathrm{~cm}^{-3}$ of a Drude oscillator. The effective mass $m^{*}$ was set to $0.275 m_{0}$ [37]. The $\mathrm{SnO}_{2}$ interband absorption was described, according to literature [28], using a high energy Lorentz oscillator with amplitude $A=1.1853$, energy position $E=5.7507 \mathrm{eV}$ and broadening $B=0.64275 \mathrm{eV}$.

The calculated reflectance of doped $\mathrm{SnO}_{2}$ in the UV, visible (vis) and near IR (NIR) spectral range is of the order of $10 \%$ (Fig. 3). Intensity oscillations due to interferences show the transparency of the coating in the UVvis range. In contrast, the IR part of the spectrum, above the plasma wavelength $\lambda_{\mathrm{P}}$, is characterized by a high reflectance due to excitation of free charge carriers. These are the desired properties for a solar-selective transmitter. The variation of $N_{\mathrm{e}}$ results in changes of $\lambda_{\text {cut-off }}$ (Fig. 3a), which for real selective materials could be defined as $\lambda$ where $50 \%$ of the maximum reflectance is reached. The variation of $\mu_{\mathrm{opt}}$ on the other hand results in different slopes of the plasma edge and therefore, in a different degree of selectivity of the films (Fig. 3b). Since there exists an optimal $\lambda_{\text {cut-off }}$ for a given absorber temperature, the charge carrier density $N_{\mathrm{e}}$ can be optimized in order to match the requirements for a maximum CSP efficiency at a specific operation temperature. However, it

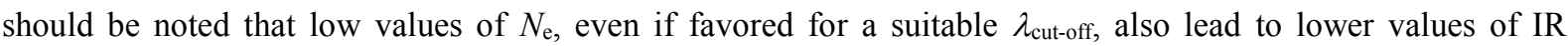
reflectance and therefore higher emissivity. The optical mobility of the charge carriers should be as high as possible, as this increases the IR reflectance, and thus, the selectivity of the coating.

Following these considerations, Ta content and deposition temperature $T_{s}$ of as-deposited $\mathrm{SnO}_{2}: \mathrm{Ta}$ samples were optimized with respect to charge carrier density and mobility by preparing two sample series as described in the experimental section (Fig. 4). 

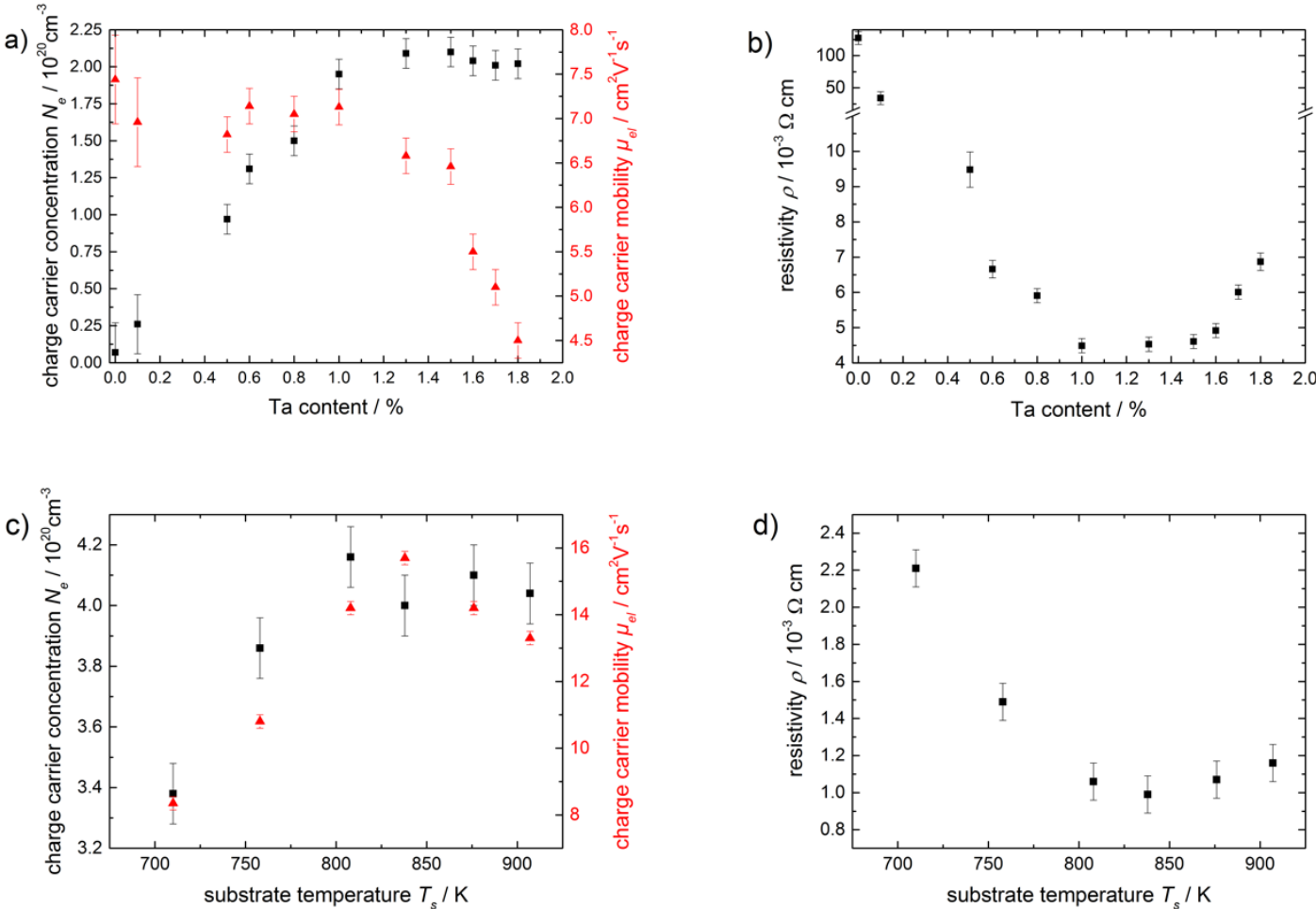

Fig. 4. Optimization of $\mathrm{SnO}_{2}:$ Ta thin film deposition parameters on fused quartz. a) Charge carrier concentration and charge carrier mobility and b) resistivity as a function of the Ta content (at.\%) at a fixed deposition temperature of $693 \mathrm{~K}$. c) Charge carrier concentration and charge carrier mobility and d) resistivity as a function of the deposition temperature at fixed Ta content of 1.2 at. $\%$.

It should be noted that optical (Fig. 3) and electrical mobility (Fig. 4) do not have to have the same value [38,39]. A discrepancy between them is indicative for different charge carrier scattering mechanisms in a sample. Electrical mobility is measured for a macroscopic sample size and is influenced by intragrain and intergrain charge carrier scattering [40]. It can be lower than the optical mobility, when the free electron path, upon electric field oscillations, is shorter than the sample's grain size. Then, only intragrain scattering occurs [41]. Nevertheless, high values of electrical mobility also imply high optical mobility, and the electrical characterization is a suitable indicator for the quality of a solar-selective TCO.

The variation of the Ta content results in a minimum of resistivity $\rho$ at approximately 1.2 at.\% (Fig. 4b), which is in perfect agreement with a previous study of radio-frequency magnetron sputtered $\mathrm{SnO}_{2}: \mathrm{Ta}^{2}$ [42]. At lower Ta concentrations, the charge carrier concentration $N_{\mathrm{e}}$ and mobility $\mu_{\mathrm{el}}$ approach the values of undoped $\mathrm{SnO}_{2}(\mathrm{Fig}$. 4a), resulting in a high resistivity (Fig. 4b). Higher Ta concentrations ( $>1.5$ at.\%) do not increase $N_{\mathrm{e}}$ considerably, but lead to decreasing $\mu_{\mathrm{el}}$ and higher resistivity. This is probably due to a higher scattering probability at the ionized Ta impurities, or clustering of the Ta ions $[43,44]$. The variation of the substrate temperature, $T_{\mathrm{s}}$, results in a minimum of $\rho$ at approximately $840 \mathrm{~K}-860 \mathrm{~K}$, which is very similar to the value of $873 \mathrm{~K}$ reported in the literature [42]. Samples deposited at lower temperatures showed low mobility and charge carrier concentration, probably due to poor crystallinity and small amount of Ta on $\mathrm{Sn}$ lattice sites. This behavior was already reported for other TCOs [44]. In conclusion, a Ta content of 1.2 at.\% and a substrate temperature of $850 \mathrm{~K}$ were established as deposition parameters to prepare optimized $\mathrm{SnO}_{2}$ :Ta TCO films. 


\subsection{Thermal stability and optical characterization of optimized, selectively-transmitting $\mathrm{SnO}_{2}$ :Ta thin films}

The optimized TCO films used for the following investigations had the composition 67.1 at.\% O, 31.6 at.\% Sn and 1.2 at.\% Ta. Their thermal stability up to a temperature of $1073 \mathrm{~K}$ was investigated in situ by SE and RBS. SE shows marginal changes in the measured ellipsometric angles (Fig. 5), which are attributed to small temperatureinduced deformations of the sample holder and the resulting slight misalignment. Thus, in situ SE provides evidence for the conservation of layer thickness and optical properties of the $\mathrm{SnO}_{2}$ :Ta thin film, both during and after high-temperature treatment.
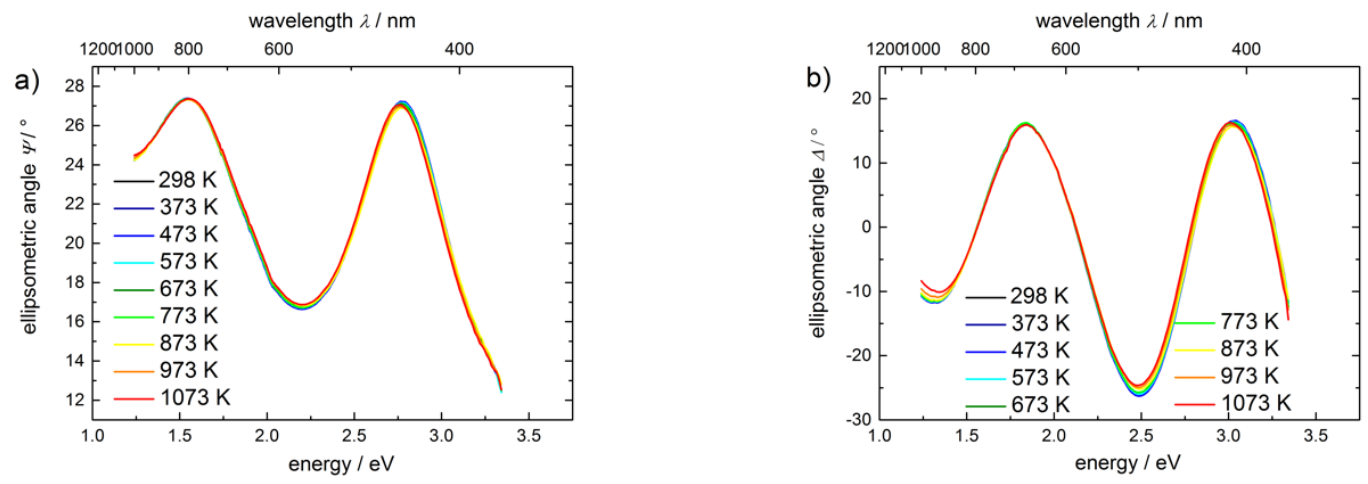

Fig. 5. Temperature dependence of the spectroscopic ellipsometry angles a) $\psi$ and b) $\Delta$ during in situ heating of a $\mathrm{SnO}_{2}: \mathrm{Ta}(1.2$ at.\% Ta) thin film on fused quartz from RT to $1073 \mathrm{~K}$.

The in-depth compositional stability of the $\mathrm{SnO}_{2}$ :Ta thin films was studied by a temperature-dependent in situ RBS experiment (Fig. 6). Minor reproducible steps of the RBS energies occurred during mapping just when the final temperature of each heating ramp was reached (Fig. 6b). At the highest temperature itself, the energies were constant, and the changes were fully reversed when re-cooling was started. Thus, the steps are attributed to the detector response at the highest temperatures. With this in mind, the pre- and post-heating spectra (Fig. 6a), as well as the in situ map (Fig. 6b), reveal the conservation of the elemental depth distribution throughout the entire film thickness over both time and temperature. In conclusion, both in situ experiments demonstrated the excellent optical and chemical stability of the $\mathrm{SnO}_{2}$ :Ta thin films at temperatures up to $1073 \mathrm{~K}$ in vacuum. Since the substrate and the antireflective layer have the same chemical composition, $\mathrm{SiO}_{2}$, these in situ investigations allow at least the well-founded assumption that neither mixing processes nor chemical reactions are to be expected between the anti-reflective layer and the TCO layer. Moreover, possible clustering or segregation processes of the dopant that can occur in doped materials at high temperatures were excluded for $\mathrm{SnO}_{2}$ :Ta (1.2 at.\% Ta) by the demonstrated temperature stability. It should be noted that there are no previous records of in situ RBS measurements at such high temperatures in the analysis of solar thermal materials. The in situ techniques applied here are ideally suitable for upcoming CSP technologies and can moreover provide important insight into failure mechanisms of coatings in general (e.g. substrate atom migration or diffusion on layer interfaces) and their dynamics, which is impossible with standard post-heating analysis. 

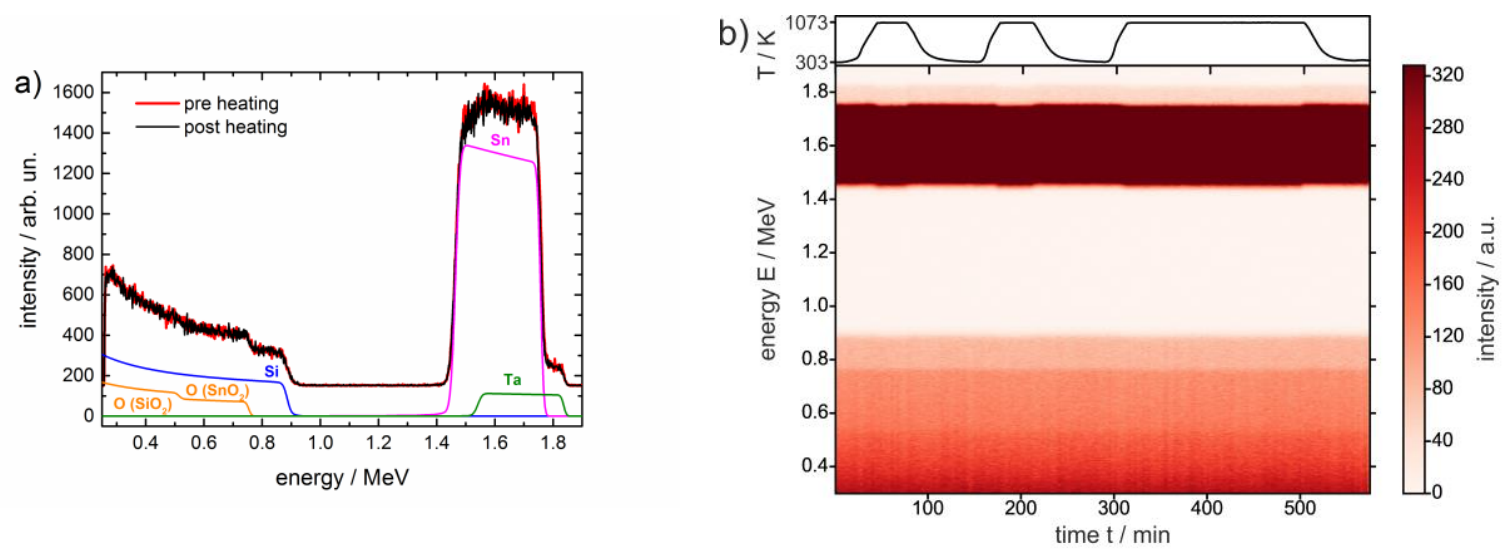

Fig. 6. Temperature dependent in situ RBS study of a $\mathrm{SnO}_{2}: \mathrm{Ta}(1.2$ at.\% $\mathrm{Ta}$ ) thin film on fused quartz in the range from $\mathrm{RT}$ to $1073 \mathrm{~K}$. a) Single RBS spectra taken at RT before and after the heating cycles to $1073 \mathrm{~K}\left(800^{\circ} \mathrm{C}\right)$ and b) in situ RBS map taken during three heating cycles between RT and $1073 \mathrm{~K}$ with a total dwell of 4 hours at the highest temperature.

For reliable optical and electrical characterization of the optimized $\mathrm{SnO}_{2}: \mathrm{Ta}$ (1.2 at.\% Ta) thin films, a series of five samples was deposited using the optimized deposition parameters described in section 3.1. Hall measurements yielded a mean charge carrier concentration of $N_{\mathrm{e}}=(4.3 \pm 0.3) \times 10^{20} \mathrm{~cm}^{-3}$ and a mean charge carrier mobility of $\mu_{\mathrm{el}}=(14 \pm 3) \mathrm{cm}^{2} \mathrm{~V}^{-1} \mathrm{~s}^{-1}$. The dielectric function was determined by means of SE and spectrophotometry, and used to build an optical model comprising the contributions of the $\mathrm{SnO}_{2}$ :Ta layer, a quartz reference substrate and a surface roughness layer on top. The latter is described by an effective medium approximation (EMA) layer, a superposition of the optical constants of a 50/50 vol.\% material/void mixture. This is a common approximation to simulate surface roughness $[45,46]$. The dielectric function of $\mathrm{SnO}_{2}: \mathrm{Ta}$ was described by a Tauc-Lorentz oscillator for intraband transitions, which, in comparison to the previously used Lorentz oscillator from the optical database, allows direct access to the optical band gap energy $E_{\text {gap }}$ of the material [47]. $E_{\text {gap }}$ of $\mathrm{SnO}_{2}: \mathrm{Ta}$ (1.2 at.\% Ta) is found to be $4.5 \mathrm{eV}$. Compared to the commonly observed value for undoped $\mathrm{SnO}_{2}, E_{\text {gap }} \approx 3.9 \mathrm{eV}$, it is increased by doping due to Burstein-Moss shift [41]. Additionally, a Drude oscillator was used to account for the free charge carrier contributions as explained in section 3.1. The excellent agreement between experimental and simulated reflectance spectrum of the optimized samples is shown in Fig. 7.

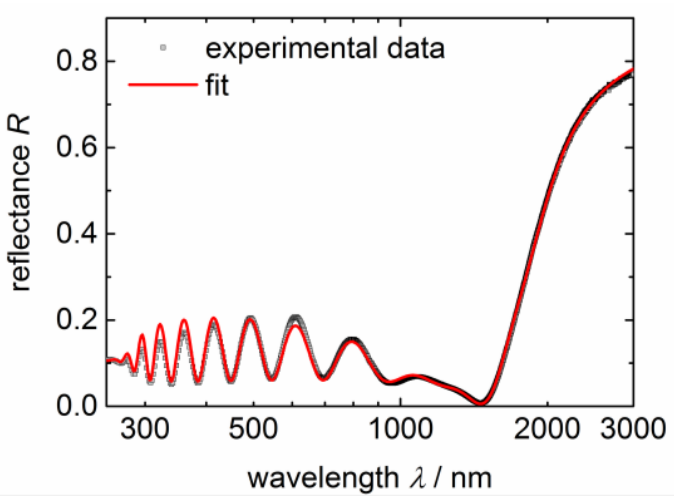

Fig. 7. Experimental and simulated reflectance of a $555 \mathrm{~nm}$ $\mathrm{SnO}_{2}: \mathrm{Ta}(1.2$ at.\% Ta) coating on fused quartz substrate.

The reflectance spectrum shows a distinct solar-selective behavior with $\lambda_{\text {cut-off }}$ at $\approx 1900 \mathrm{~nm}$. The average charge carrier concentration determined by optical analysis of $\mathrm{SnO}_{2}: \mathrm{Ta}\left(1.2\right.$ at.\% Ta) is $N_{\mathrm{e}}=(4.4 \pm 0.2) \times 10^{20} \mathrm{~cm}^{-3}$, which is in good agreement with the electrically measured value of $N_{\mathrm{e}}$. On the other hand, the optical and electrical charge carrier mobilities differ, with $\mu_{\mathrm{opt}}=(35 \pm 3) \mathrm{cm}^{2} \mathrm{~V}^{-1} \mathrm{~s}^{-1}$ and $\mu_{\mathrm{el}}=(14 \pm 3) \mathrm{cm}^{2} \mathrm{~V}^{-1} \mathrm{~s}^{-1}$, for reasons explained in the 
previous section $[39,48]$. These results further show the films are highly suited to provide solar selectivity (Fig 3 . and Fig. 7).

\subsection{Optimization of the $\mathrm{SnO}_{2}$ :Ta thin film as selectively-transmitting coating}

In order to optimize the $\mathrm{SnO}_{2}: \mathrm{Ta}(1.2$ at.\% $\mathrm{Ta}$ ) thin film as selectively-transmitting coating, the effect of an $\mathrm{AR}$ coating on top of the TCO was explored. According to Fresnel's equations, small differences of refractive indices $n$ at an interface lead to low reflectance. Thus, $\mathrm{SiO}_{2}$ with $1.42<n<1.50$ in the solar range is a suitable material for this purpose, if deposited on a $\mathrm{SnO}_{2}$ :Ta layer with a refractive index of $0.5<n<2.1$, as determined in this work from ellipsometry and reflectivity measurements in the range 0.5 to $5 \mathrm{eV}$. Fig. 8a shows the change of reflectance of a $805 \mathrm{~nm}$ thick $\mathrm{SnO}_{2}$ :Ta layer on fused quartz when a $50 \mathrm{~nm}$ thick $\mathrm{AR}$ layer of $\mathrm{SiO}_{2}$ is deposited on top. Fig. 8b displays the calculated absorptivity of the AR/ TCO/ fused quartz system as a function of the AR layer thickness. It is evident that the absorptivity of the layer stack is increased from 0.89 to a maximum of 0.96 for a $90 \mathrm{~nm}$ thick $\mathrm{SiO}_{2}$ AR layer, after which it decreases. The remaining loss of $4 \%$ results from the reflection at the AR layer in the solar range. It cannot be further reduced by optimizing thicknesses [49]. The simulated effect of the AR layer was experimentally confirmed by the absorptivity enhancement from $\alpha=0.90$ for the bare TCO on

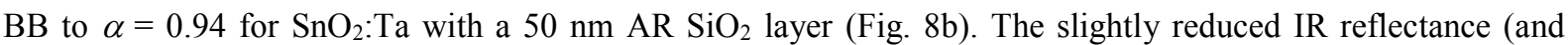
therefore higher emissivity $\varepsilon$ ) of $<5 \%$ (Fig. 8a) is negligible compared to a similar percentage of absorptivity increase. Additionally, the nonreactive $\mathrm{SiO}_{2}$ layer is very likely to ensure thermal stability even under atmospheric conditions.

Having found the favorable AR layer thickness, the influence of the TCO layer thickness and of the film roughness were studied. Therefore, the absorptivity was experimentally studied as a function of the TCO layer thickness (Fig. 8c and 8d). The thickness and roughness effect were then simulated for the model system ideal BB $(\alpha=1)$, optimized TCO and AR surface layer with and without roughness as a function of $\mathrm{SnO}_{2}$ :Ta thickness (Fig. 8c and 8d). Simulations of different $\mathrm{SnO}_{2}: \mathrm{Ta}$ thicknesses without taking surface roughness into account gave an absorptivity minimum at $300 \mathrm{~nm}$ due to interference effects, but the overall variation of $\alpha$ in the considered film thickness range from $200 \mathrm{~nm}$ to $10000 \mathrm{~nm}$ is less than $1 \%$ and therefore marginal (Fig. 8d, open squares). However, the experimental data show a larger variation of $\alpha$ when the TCO thickness increased from $290 \mathrm{~nm}$ to $1285 \mathrm{~nm}$. This can be attributed to a simultaneous roughness increase from $8 \mathrm{~nm}$ to $30 \mathrm{~nm}$. Modelling the roughness of the deposited samples gives a much better agreement between experimental and simulated data (Fig. 8d, open circles). In the simulation, the roughness varied from $6 \mathrm{~nm}$ to $80 \mathrm{~nm}$ for the simulated TCO thickness range from $200 \mathrm{~nm}$ to $10000 \mathrm{~nm}$. The roughness layer acts as an anti-reflective coating as it consists of $50 \% \mathrm{SnO}_{2}$ :Ta and 50 $\%$ voids and can therefore be thought of as a material with reduced refractive index. Hence, the roughness of the TCO layer should be known in order to apply an AR layer with optimal thickness to maximize absorptivity. The independence of the performance on the film thickness itself, however, is a big advantage of the TCO on BB configuration in comparison to other selective absorbers, which usually have to meet very precise thickness requirements in the designed multilayer stacks. 

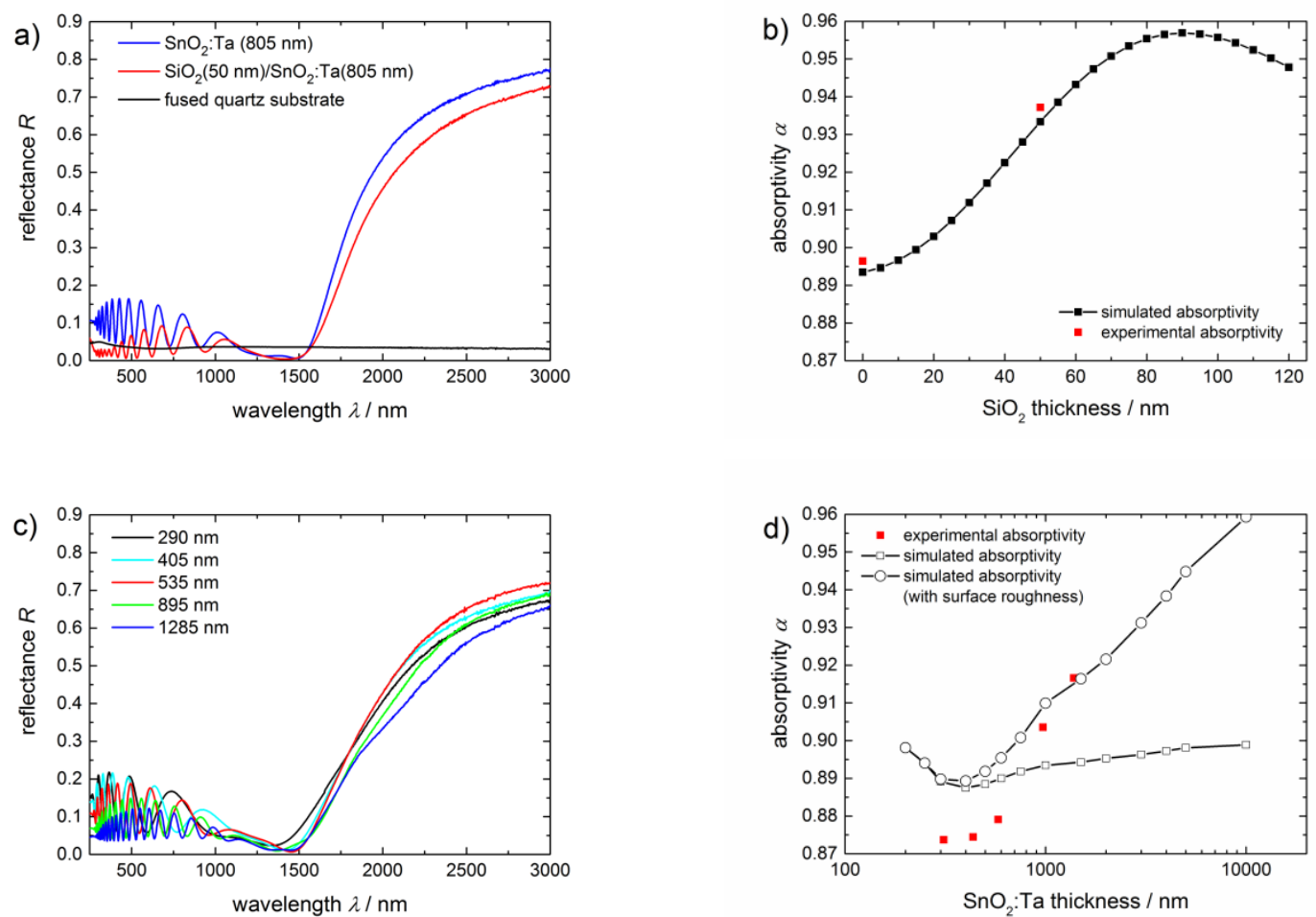

Fig. 8. Influence of an antireflective $\mathrm{SiO}_{2}$ top layer on the measured reflectance (a) and the calculated absorptivity (b), and influence of the $\mathrm{SnO}_{2}$ :Ta layer thickness on the measured reflectance (c) and the calculated absorptivity (d). The absorptivities were obtained assuming a perfect $\mathrm{BB}$ absorber beneath the TCO with and without roughness.

\subsection{Proof of concept for selectively transmitting coatings on top of a pure absorber}

It is now an interesting question, whether non-selective absorber materials can be transformed into solar-selective one's by the developed TCO. Therefore, a $320 \mathrm{~nm}$ thick $\mathrm{SnO}_{2}$ :Ta layer was deposited on top of a silicon wafer and a glassy carbon substrate.
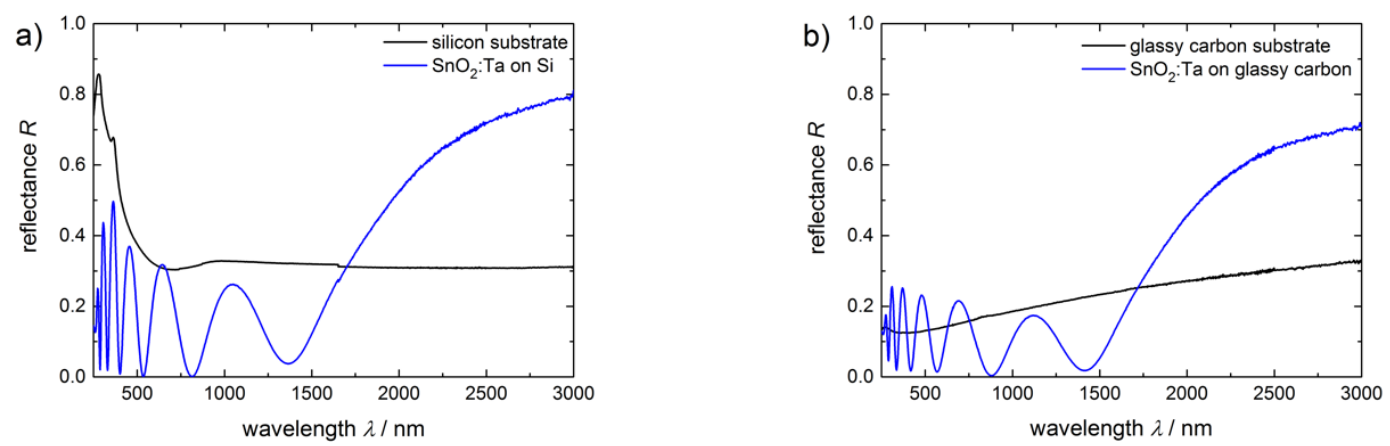

Fig. 9. Reflectance of bulk and of $\mathrm{SnO}_{2}$ :Ta-coated $(320 \mathrm{~nm})$ a) silicon and b) glassy carbon substrates showing the transformation of the two materials into solar-selective absorbers by depositing the TCO on top of them.

$\mathrm{Si}$ and glassy carbon are absorbers with absorptivities of 0.65 and 0.83 , respectively. Both have low reflectance in the IR range, and thus, are lacking of solar selectivity (Fig. 9a and 9b). After deposition of a $\mathrm{SnO}_{2}: \mathrm{Ta}$ thin film on top of them, the layer stacks exhibit distinct solar-selective behavior: enhanced absorptivity of $0.81\left(\mathrm{SnO}_{2}: \mathrm{Ta}_{\mathrm{on}}\right.$ $\mathrm{Si})$ and $0.86\left(\mathrm{SnO}_{2}:\right.$ Ta on glassy carbon $)$, a $\lambda_{\text {cut-off }}$ of $\approx 1800 \mathrm{~nm}$ and high reflectance, i.e. reduced emissivity in the IR. The absorptivity enhancement is due to the previously described anti-reflective effect of the $\mathrm{SnO}_{2}: \mathrm{Ta}$. In 
particular the $\mathrm{Si} /$ air $\left.\left(n_{\mathrm{Si}, 300 ~ n m}=5.1 ; n_{\mathrm{Si}, 2500 \mathrm{~nm}}=3.4[50]\right) / n_{\text {air }}=1.0\right)$ interface is replaced by a $\mathrm{SnO} 2: \mathrm{Ta} /$ air $\left(n_{\mathrm{SnO}: \mathrm{Ta}}\right.$ $\left.300 \mathrm{~nm}=2.1 ; n_{\mathrm{SnO} 2 \mathrm{Ta}, 2500 \mathrm{~nm}}=0.5\right)$ and a Si $\mathrm{SnO}_{2}:$ Ta interface, leading to an absorptivity increase of $25 \%$. These results show yet another advantage of the TCO on BB absorber concept, as all absorbing materials could be turned into solar-selective absorbers, provided that their surface roughness is low compared to the TCO thickness.

\subsection{Comparison of the solar conversion efficiency: selectively transmitting TCO on a black body absorber vs. bare black body absorber}

According to Equation 2, the evaluation of the optical efficiency of a solar absorber also requires the knowledge of the emissivity. Simulations of the IR reflectance based on the optical model presented in section 3.2 were applied to calculate $\varepsilon$ of the TCO on top of a perfect BB substrate. According to Equation $1 \mathrm{~b}$ the emissivity of $\mathrm{SiO}_{2}(90$ $\mathrm{nm}) / \mathrm{SnO}_{2}: \mathrm{Ta}(1000 \mathrm{~nm})$ at $1073 \mathrm{~K}$ is $\varepsilon=0.265$. As a conservative estimation $\varepsilon=0.30$ and $\alpha=0.95$ were used to compare the solar energy to mechanical energy conversion efficiencies of the bare BB and the TCO on BB concept. The following configurations were compared: a) $\mathrm{SiO}_{2}(90 \mathrm{~nm}) / \mathrm{SnO}_{2}: \mathrm{Ta}(1000 \mathrm{~nm})$ coated $\mathrm{BB}(\alpha=0.95, \varepsilon=0.3)$ and $\mathrm{b})$ uncoated non-selective $\mathrm{BB}(\alpha=1, \varepsilon=1)$. The efficiencies, $\eta$, of the two model systems were calculated using Equation 2 and are displayed for a relevant $\left(C, T_{H}\right)$ parameter space in Fig. 10. Numeric efficiency values for selected $\left(C, T_{H}\right)$ combinations are listed in Table 1 and Table 2.

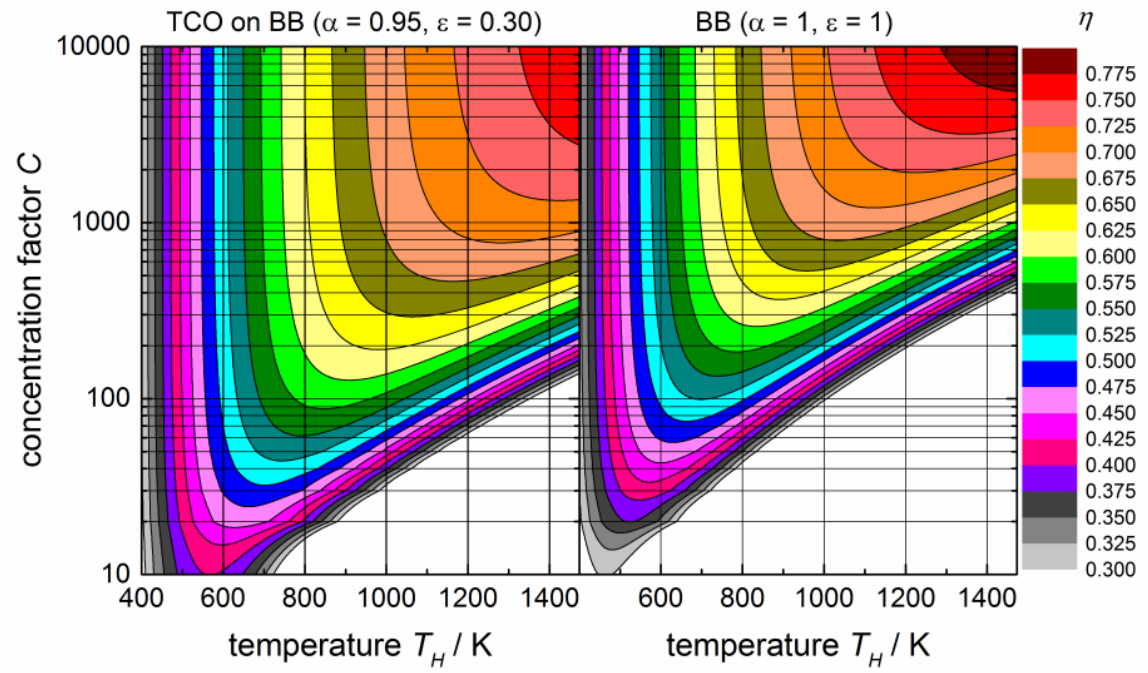

Fig. 10. Solar energy to mechanical energy conversion efficiency $(\eta)$ maps of a $\mathrm{SiO}_{2}(90 \mathrm{~nm}) / \mathrm{SnO}_{2}: \mathrm{Ta}(1000 \mathrm{~nm})$ coated $\mathrm{BB}$ absorber $(\alpha=0.95, \varepsilon=0.3)$, (left panel) and a non-selective BB absorber $(\alpha=1, \varepsilon=1)$, (right panel) as function of concentration factor $C$ and absorber temperature $T$.

For the discussion of this comprehensive data set, i) the efficiency $\eta$ for a given parameter combination of $C$ and $T_{\mathrm{H}}$ and ii) the maximum efficiency achievable for a given $C$ value, $\eta_{\max }$, are used. While the former value represents a pure performance parameter, the latter can be associated with the number of mirrors necessary to achieve a certain solar plant efficiency. As such, the maximum efficiency is of predictive value for the design of CSP plants. The most general conclusion from Fig. 10 is that the TCO on BB configuration leads to higher efficiencies for lower concentration factors. Going through the results from high to low concentration factors, for $10000>C>$ 4000 the emissivity reduction due to the TCO cannot compensate the lowered absorptivity and thus, the TCO coating even worsens the overall CSP efficiency. In the range of $4000>C>1000$ the TCO coating can improve the efficiency at temperatures above $1100 \mathrm{~K}$. However, there are no commercial CSP plants operating at these 
concentration factors and temperatures yet. At $1000>C>100$, which are typical values for central receiver tower plants in operation or under construction, the TCO coated system achieves similar or higher efficiencies in the whole temperature range. At the target temperature, $T_{\mathrm{H}}=1073 \mathrm{~K}$, the improvement of the absolute efficiency is 0.36 for $C=100$ (Table 1). However, the maximum efficiencies for $C=100$ are achieved at even lower temperatures: $\eta_{\max , \mathrm{TCO} / \mathrm{BB}}=0.58\left(T_{H}=870 \mathrm{~K}\right)$ and $\eta_{\max , \mathrm{BB}}=0.53\left(T_{H}=700 \mathrm{~K}\right)$. This corresponds to a relative efficiency improvement of $>9 \%$ due to the TCO. For $100>C>10$, which covers the typical concentration factors of parabolic trough systems, a large improvement in efficiency can be achieved for all temperatures considered in this work. The maximum efficiencies at $C=10$ are $\eta_{\max }, \mathrm{TCO} / \mathrm{BB}=0.40\left(T_{H}=570 \mathrm{~K}\right)$ and $\eta_{\max }, \mathrm{BB}=0.30(T=460$ $\mathrm{K})$, respectively, corresponding to a TCO-caused relative improvement of $33 \%$.

Table 1. Comparison of efficiencies of a $\mathrm{SiO}_{2}(90 \mathrm{~nm}) / \mathrm{SnO}_{2}: \mathrm{Ta}(1000 \mathrm{~nm})$ coated $\mathrm{BB}$ absorber $\left(\eta_{T C O / B B ;} \alpha=0.95, \varepsilon=0.3\right)$ and a non-selective BB absorber ( $\left.\eta_{\mathrm{BB} ;} \alpha=1, \varepsilon=1\right)$ at the targeted temperature $T_{\mathrm{H}}=1073 \mathrm{~K}$ for different concentration factors $(C)$.

\begin{tabular}{llll}
\hline$C$ & $\eta_{\mathrm{TC} / \mathrm{BB}}$ & $\eta_{\mathrm{BB}}$ & $\eta_{\mathrm{TCO} / \mathrm{BB}}-\eta_{\mathrm{BB}}$ \\
\hline 100 & 0.54 & 0.18 & 0.36 \\
200 & 0.62 & 0.47 & 0.15 \\
300 & 0.65 & 0.56 & 0.09 \\
500 & 0.67 & 0.63 & 0.04 \\
1000 & 0.69 & 0.69 & 0 \\
5000 & 0.70 & 0.73 & -0.03 \\
10000 & 0.71 & 0.74 & -0.03 \\
\hline
\end{tabular}

Table 2. Comparison of efficiencies of a $\mathrm{SiO}_{2}(90 \mathrm{~nm}) / \mathrm{SnO}_{2}: \mathrm{Ta}(1000 \mathrm{~nm})$ coated BB absorber $\left(\eta_{\mathrm{TCO} / \mathrm{BB}} ; \alpha=0.95, \varepsilon=0.3\right)$ and a non-selective BB absorber ( $\left.\eta_{\mathrm{BB}} ; \alpha=1, \varepsilon=1\right)$ for different operation temperatures $\left(T_{\mathrm{H}}\right)$ and two concentration factors, $C$ $=100$, and $C=1000$.

\begin{tabular}{lllllll}
\hline$T_{\mathrm{H}}[\mathrm{K}]$ & $\begin{array}{l}\eta_{\mathrm{TCO} / \mathrm{BB}} \\
(C=100)\end{array}$ & $\begin{array}{l}\eta_{\mathrm{BB}} \\
(\mathrm{C}=100)\end{array}$ & $\begin{array}{l}\eta_{\mathrm{TCO} / \mathrm{BB}}-\eta_{\mathrm{BB}} \\
(C=100)\end{array}$ & $\begin{array}{l}\eta_{\mathrm{TCO} / \mathrm{BB}} \\
(C=1000)\end{array}$ & $\begin{array}{l}\eta_{\mathrm{BB}} \\
(C=1000)\end{array}$ \\
\hline 400 & 0.30 & 0.31 & -0.01 & 0.30 & 0.32 & -0.02 \\
600 & 0.51 & 0.50 & 0.01 & 0.52 & 0.54 & -0.02 \\
800 & 0.58 & 0.51 & 0.07 & 0.62 & 0.64 & -0.02 \\
1000 & 0.57 & 0.31 & 0.26 & 0.68 & 0.69 & 0.68 \\
1200 & 0.46 & - & 0.46 & 0.71 & 0.71 & 0.62 \\
1400 & 0.24 & - & 0.24 & 0.03 & 0.09 \\
\hline
\end{tabular}

Looking at the results of Fig. 10 from another perspective, equal efficiencies are achieved at lower concentration factors by the $\mathrm{TCO} / \mathrm{BB}$ system, with the consequence of operating the absorber at higher temperatures. For example, $\eta=0.55$ is reached with $C=60$ instead of $C=135$, accompanied by increasing $T_{\mathrm{H}}$ from $740 \mathrm{~K}$ to 790 $\mathrm{K}$. Taking the target temperature $\left(T_{H}=1073 \mathrm{~K}\right)$ of this work as a maximum operation temperature, $\eta_{\max }=0.66$ can be achieved with $C=335$ compared to $C=620$ for the non-selective system at $T_{H}=970 \mathrm{~K}$. This corresponds to a reduction in $C$ by more than $45 \%$. 


\section{Conclusion}

The concept of using a solar-selective TCO on top of a black body was explored for mid- and high-temperature CSP technology. Optimized films of $\mathrm{SnO}_{2}:$ Ta were developed, whose cut-off wavelength $\lambda_{\text {cut-off }}$ and spectral selectivity were shown to be tunable in the relevant solar range. In situ SE and RBS measurements demonstrated the compositional, optical and structural stability of the TCO up to $1073 \mathrm{~K}$ in vacuum. Its performance was shown to be thickness-independent in a range from several hundred nanometers to microns. Hence, the effort of manufacturing very precise layer thicknesses that is required for complex multilayer structures of state-of-the art SSCs is avoided. The optimized $\mathrm{SnO}_{2}: \mathrm{Ta} / \mathrm{SiO}_{2}$ layer stack of this study has reflective losses of $<5 \%$. When applied on a non-selective BB substrate $(\alpha=1, \varepsilon=1)$, the BB's emissivity decreases to $\varepsilon \leq 30 \%$. The comparison of the energy conversion efficiency of the entire $\mathrm{BB} / \mathrm{TCO} / \mathrm{AR}$ layer stack with conservative values for absorptivity and emissivity, $\alpha=0.95$ and $\varepsilon=0.30$, with that of an ideal BB revealed potential application ranges of the developed coating for a wide parameter space of solar concentration factor, $C$, and absorber temperature, $T_{\mathrm{H}}$. Systems with $1000>C>100$ can be improved by up to 0.05 considering absolute maximum efficiencies $\eta_{\text {max }}$. The highest absolute efficiency improvements of $0.05-0.10$ are possible for $C<100$, which is typical for parabolic trough systems. Equal efficiencies in combination with higher absorber temperatures can be obtained with a significant reduction of the sun concentration factor, $C$. At absorber temperatures from $570 \mathrm{~K}$ up to the targeted value of this work $\left(T_{\mathrm{H}}=1073 \mathrm{~K}\right)$, this reduction in $C$ amounts to $46 \%$ to $60 \%$. The improvement could be translated into significantly lower levelized costs of electricity produced by solar power plants by reducing the number of mirrors, the areal footprint, management costs and last but not least the costs of mirror maintenance. It has to be emphasized at this point that the comparison with a perfect black body is the worst-case scenario for the $\mathrm{SnO}_{2}$ :Ta system, since the $\mathrm{BB}$ absorptivity is inherently less than 1 for real materials with substantial negative consequences for its efficiency.

The universality of the selective transmitter concept was experimentally proven by the deposition of the TCO on bare absorbing surfaces, namely silicon and glassy carbon, which showed distinct solar-selective optical response thereafter. Hence, non-selective absorber materials can be turned into selective absorbers. Additionally, the performance of the TCO is independent on its thickness. Both these properties are very attractive from an application point of view. The excellent TCO properties open the opportunity of applying this concept as an alternative to currently used non-selective absorbers and even to solar-selective coatings based on complex multilayer structures of oxides or nitrides. Finally, compared to currently used pigment paints which have a higher initial efficiency but suffer from relatively fast degradation over time, the robust thermal and structural stability of our films is another strong argument to their deployment in the concentrated solar power plant industry.

\section{Acknowledgements}

Support of the Ion Beam Center (IBC) and its operator team at HZDR as well as technical assistance by A. Schneider and J. Zscharschuch are gratefully acknowledged. The authors thank our colleagues Dr. Sonia Fereres Rapaport (Abengoa S.L.) and Dr. Ciarán Fowley (HZDR) for careful proofreading of correct English language style by native speakers. This work was financially supported by the EU H2020 RISE project "Framework of 
Innovation for Engineering of New Durable Solar Surfaces (FRIENDS ${ }^{2}$, GA-645725)" and the Initiative and Networking Funds of the president of the Helmholtz Association via the W2/W3 program (SG).

\section{References}

[1] National Renewable Energy Laboratory, Concentrating Solar Power Projects with Operational Plants, https://www.nrel.gov/csp/solarpaces/projects_by_status.cfm?status=Operational, accessed: April, 2018.

[2] C. E. Kennedy, Review of Mid- to High-Temperature Solar Selective Absorber Materials, Technical Report of the National Renewable Energy Laboratory 2002, NREL/TP-520-31267.

[3] C. G. Granqvist, Solar Energy Materials, Adv. Mater. $15 \quad$ (2003) 1789-1803, doi:10.1002/adma.200300378.

[4] C. G. Granqvist, Transparent Conductors as Solar Energy Materials: A panoramic view, Sol. Energy Mater. \& Solar Cells 91 (2007) 1529-1598, doi:10.1016/j.solmat.2007.04.031.

[5] L. A. Weinstein, J. Loomis, B. Bhatia, D. M. Bierman, E. N. Wang, G. Chen, Concentrating Solar Power, Chem. Rev. 115 (2015) 12797-12838, 10.1021/acs.chemrev.5b00397.

[6] National Renewable Energy Laboratory, Reference Solar Spectral Irradiance, http://rredc.nrel.gov/solar/spectra/am1.5/ASTMG173/ASTMG173.html, accessed: April, 2018

[7] The World Scientific Handbook of Energy, Volume 3: Materials and Energy, Eds. Gerard M Crawley, University of South Carolina, USA), doi.org/10.1142/8114, 2013, see page 199

[8] Goswami, D. (Ed.). (2004). The CRC Handbook of Mechanical Engineering. Boca Raton: CRC Press, https://doi.org/10.1201/9781420041583

[9] R. Escobar-Galindo, I. Heras, G. Rincón-Llorente, M. Alcón-Camas, F. Lungwitz, F. Munnik, E. Schumann, I. Azkona, M. Krause, Design of High-Temperature Solar-Selective Coatings Based on Aluminium Titanium Oxynitrides $\mathrm{Al}_{\mathrm{y}} \mathrm{Ti}_{1-\mathrm{y}}\left(\mathrm{O}_{\mathrm{x}} \mathrm{N}_{1-\mathrm{x}}\right)$. Part 2: Experimental Validation and Durability Tests at High Temperature, Sol. Energy Mater. \& Solar Cells 185 (2018) 183-191, doi:10.1016/j.solmat.2018.04.027.

[10] M. Lopez-Herraiz, A. B. Fernandez, N. Martinez, M. Gallas, Effect of the Optical Properties of the Coating of a Concentrated Solar Power Central Receiver on its Thermal Efficiency, Sol. Energy Mater. \& Solar Cells 159 (2017) 66-72, doi:10.1016/j.solmat.2016.08.031.

[11] American Society for Testing and Materials, ASTM E903-12 2012, ASTM

International, West Conshohocken, PA, www.astm.org.

[12] EU Standard, N. Europeenne, UNE-EN 673, 2011.

[13] H. C. Barshilia, N. Selvakumar, K. S. Rajam, D. V. Sridhara Rao, K. Muraleedharam, Deposition and Characterization of TiAlN/TiAlON/Si ${ }_{3} \mathrm{~N}_{4}$ Tandem Absorbers Prepared Using Reactive Direct Current Magnetron Sputtering, Thin Solid Films 516 (2008) 6071-6078, doi:10.1016/j.tsf.2007.10.113.

[14] N. Selvakumar, H. C. Barshilia, K. S. Rajam, A. Biswas, Structure, Optical Properties and Thermal Stability of Pulsed Sputter Deposited High Temperature $\mathrm{HfO}_{\mathrm{x}} / \mathrm{Mo} / \mathrm{HfO}_{2}$ Solar Selective Absorbers, Sol. Energy Mater. \& Solar Cells 94 (2010) 1412-1420, doi:10.1016/j.solmat.2010.04.073.

[15] L. Rebouta, A. Sousa, M. Andritschky, F. Cerqueira, C. J. Tavares, P. Santilli, K. Pischow, Solar Selective Absorbing Coatings Based on AlSiN/AlSiON/AlSiO y Layers, Appl. Surf. Sci. 356 (2015) 203-212, dx.doi.org/10.1016/j.apsusc.2015.07.193. 
[16] Q.-C. Zhang, V. Yin, D. R. Mills, High Efficiency Mo- $\mathrm{Al}_{2} \mathrm{O}_{3}$ Cermet Selective Surfaces for HighTemperature Application, Sol. Energy Mater. \& Solar Cells 40 (1996) 43-53, doi:10.1016/0927-0248(95)00078$\mathrm{X}$.

[17] C. A. Arancibia-Bulnes, C. A. Estrada, J. C. Ruiz-Suárez, Solar Absorptance and Thermal Emittance of Cermets with Large Particles, J. Phys. D 33 (2000) 2489-2496, doi:10.1088/0022-3727/33/19/320.

[18] B. O. Seraphin, Chemical Vapor Deposition of Thin Semiconductor Films for Solar Energy Conversion, Thin Solid Films 39 (1976) 87-94, doi:10.1016/0040-6090(76)90626-X.

[19] K. Zhang, L. Hao, M. Du, J. Mi, J.-N. Wang, J.-P. Meng, A Review on Thermal Stability and High Temperature Induced Ageing Mechanisms of Solar Absorber Coatings, Renew. Sustain. Energy Rev. 67 (2017) 1282-1299, doi:10.1016/j. rser.2016.09.083.

[20] I. Heras, E. G., F. Lungwitz, G. Rincón-Llorente, F. Munnik, E. Schumann, I. Azkona, M. Krause, R. Escobar-Galindo, Design of High-Temperature Solar-Selective Coatings Based on Aluminium Titanium Oxynitrides $\mathrm{Al}_{\mathrm{y}} \mathrm{Ti}_{1-\mathrm{y}}\left(\mathrm{O}_{\mathrm{x}} \mathrm{N}_{1-\mathrm{x}}\right)$. Part 1: Advanced Microstructural Characterization and Optical Simulation, Sol. Energy Mater. \& Solar Cells 176, 81-92 (2018), doi:10.1016/j.solmat.2017.10.015.

[21] A. Rodriguez-Palomo, E. Cespedes, D. Hernandez-Pinilla, C. Prieto, High-Temperature Air-Stable Solar Selective Coating Based on $\mathrm{MoSi}_{2}-\mathrm{Si}_{3} \mathrm{~N}_{4}$ composite, Sol. Energy Mater. \& Solar Cells 174 (2018) 50-55, doi:10.1016/j.solmat.2017.08.021.

[22] J. J. Coumo, J. F. Ziegler, J. M. Woodall, A New Concept for Solar Energy Thermal Conversions, Appl. Phys. Lett. 26 (1975) 557-559, doi:10.1063/1.87990.

[23] R. A. Taylor, Y. Hewakuruppu, D. DeJarnette, T. P. Otanicar, Comparison of Selective Transmitters for Solar Thermal Applications, Appl. Opt. 55 (2016) 3829-3839, dx.doi.org/10.1364/AO.55.003829.

[24] J. C. C. Fan, F. Bachner, Transparent Heat Mirrors for Solar-Energy Applications, Appl. Opt. 15 (1976) 1012-1017, doi:10.1364/AO.15.001012

[25] H. Haitjema, J. Elich, The Physical Properties of Fluorine-Doped Tin Dioxide Films and the Influence of Ageing and Impurity Defects, Sol. Energy Mater. 16 (1987) 79-90, doi:10.1016/0165-1633(87)90010-4.

[26] M. Shimizu, M. Suzuki, F. Iguchi, H. Yugami, High Spectral Selectivity for Solar absorbers Using a Monolayer Transparent Conductive Oxide Coated on a Metal substrate, J. Appl. Phys. 121 (2017), 183103, doi.org/10.1063/1.4983189.

[27] R. G. Gordon, Criteria for Choosing Transparent Conductors, MRS Bulletin 25 (2000) 52-57, doi.org/10.1557/mrs2000.1512000.151

[28] B. Johs, C. Herzinger, B. Guenther, WVASE32 version 3.778 (J.A. Woollam Co. Inc., 2013).

[29] R. Wenisch, In Situ and Ex Situ Investigations of Transition Metal-Catalyzed Crystallization of Carbon and Silicon Thin Films, PhD Thesis, Technische Universität Chemnitz, November, 2017.

[30] R. Wenisch, F. Lungwitz, D. Hanf, R. Heller, J. Zscharschuch, R. Hübner, J. v. Borany, G. Abrasonis, S. Gemming, R. Escobar Galindo, M. Krause, Cluster Tool for In Situ Processing and Comprehensive Characterization of Thin Films at High Temperatures, Anal. Chem. 90 (2018) 7837-7842, doi:10.1021/acs.analchem.8b00923.

[31] HZDR, Equipment Nanocomposite Materials Group, https://www.hzdr.de/db/Cms?pNid=545, accessed April, 2017.

[32] L. v. d. Pauw, A Method of Measuring the Resistivity and Hall Coefficient on Lamellae of Arbitrary Shape, Philips Technical Review 20 (1958) 220-224. 
[33] P. Grosse, Freie Elektronen in Festkörpern, Springer, Berlin, Heidelberg, New York 1979.

[34] H. Kuzmany, Solid State Spectroscopy - An Introduction, Springer, Berlin Heidelberg, New York 1998.

[35] E. D. Palik, Handbook of Optical Constants of Solids, Elsevier 1997.

[36] Y. Sago, H. Fujiwara, Mapping Characterization of $\mathrm{SnO}_{2}: \mathrm{F}$ Transparent Conductive Oxide Layers by Ellipsometry Technique, Jpn. J. Appl. Phys. 2012, 51, 10NB01-1-5, dx.doi.org/10.1143/JJAP.51.10NB01.

[37] K. J. Button, C. G. Fonstad, W. Dreybrodt, Determination of the Electron Masses in Stannic Oxide by Submillimeter Cyclotron Resonance, Phys. Rev. B 4 (1971) 4539-4542, doi:10.1103/PhysRevB.4.4539.

[38] D. H. Zhang, H. L. Ma, Scattering Mechanisms of Charge Carriers in Transparent Conductive Oxide Films, Appl. Phys. A 62 (1996) 487-492, doi:10.1007/BF01567122.

[39] J. Steinhauser, S. Fay, N. Oliveira, E. Vallat-Sauvain, C. Ballif, Transition Between Grain Boundary and Intragrain Scattering Transport Mechanisms in Boron-Doped Zinc Oxide Thin Films, Appl. Phys. Lett. 90 (2007) 142107-1-3, doi.org/10.1063/1.2719158.

[40] J. Y. W. Seto, The Electrical Properties of Polycrystalline Silicon Films, J. Appl. Phys. 46 (1975) 52475254, doi:10.1063/1.321593.

[41] T. J. Coutts, D. L. Young, T. A. Gessert, D. S. Ginley, H. Hosono, Handbook of Transparent Conductors, Springer, New York, Heidelberg, Dordrecht, London, 2010.

[42] M. Weidner, J. Jia, Y. Shigesato, A. Klein, Comparative Study of Sputter-Deposited $\mathrm{SnO}_{2}$ Films Doped with Antimony or Tantalum, Phys. Status Solidi B 253 (2016) 923-928, doi:10.1002/pssb.201552720.

[43] G. Masetti, M. Severi, S. Solmi, Modeling of Carrier Mobility Against Carrier Concentration in Arsenic, Phosphorus, and Boron-Doped Silicon, IEEE Trans. Electron Devices ED-30 (1983) 764-769, doi:10.1109/TED.1983.21207.

[44] S. Cornelius, M. Vinnichenko, N. Shevchenko, A. Rogozin, A. Kolitsch, W. Möller, Achieving High Free Electron Mobility in Al:ZnO Thin Films Grown by Reactive Pulsed Magnetron Sputtering, Appl. Phys. Lett. 94 (2009) 042103-1-3, doi.org/10.1063/1.3074373.

[45] I. Volintiru, M. Creatore, M. C. M. van de Sanden, In situ spectroscopic ellipsometry growth studies on the Al-doped $\mathrm{ZnO}$ films deposited by remote plasma-enhanced metalorganic chemical vapor deposition, J. Appl. Phys. 103 (2008) 033704, doi.org/10.1063/1.2837109.

[46] L. Yuanbin, J. Qiu, L. Liu, Applicability of the effective medium approximation in the ellipsometry of randomly micro-rough solid surfaces, Opt. Express 26, (2018) 16560-16571, doi.org/10.1364/OE.26.016560.

[47] P. I. Rovira, R. W. Collins, Analysis of Specular and Textured $\mathrm{SnO}_{2}: \mathrm{F}$ Films by High Speed FourParameter Stokes Vector Spectroscopy, J. Appl. Phys. 85 (1999) 2015-2025, doi:10.1063/1.369496.

[48] M. Guglielmi, E. Menegazzo, M. Paolizzi, G. Gasparro, D. Ganz, J. Putz, M. A. Aegerter, L. HubertPfalzgraf, C. Pascual, A. Duran, H. X. Willems, M. Van Bommel, L. Buttgenbach, L. Costa, Sol-Gel Deposited Sb-Doped Tin Oxide Films, J. Solgel Sci. Technol. 13 (1998) 679-983, doi:10.1023/a:1008636804449.

[49] B.-S. Chiou, J.-H. Tsai, Antireflective Coating for ITO Films Deposited on Glass Substrate, J. Mater. Sci. - Mater. Electron. 10 (1999) 491-495, doi:10.1023/A:1008924018328.

[50] C. M. Herzinger, B. Johs, W. A. McGahan, J. A. Woollam, W. Paulson, Ellipsometric Determination of Optical Constants for Silicon and Thermally Grown Silicon Dioxide via a Multi-Sample, Multi-Wavelength, Multi-Angle Investigation, J. App. Phys. 83 (1998) 3323-3336, doi:10.1063/1.367101. 